\title{
Molecular Imaging of Early $\alpha_{v} \beta_{3}$ Integrin Expression Predicts Long-Term Left-Ventricle Remodeling After Myocardial Infarction in Rats
}

\author{
Hossam M. Sherif ${ }^{1,2 *}$, Antti Saraste ${ }^{1,3 *}$, Stephan G. Nekolla ${ }^{1}$, Eliane Weidl ${ }^{1}$, Sybille Reder ${ }^{1}$, Arne Tapfer $^{1}$, \\ Martina Rudelius ${ }^{4}$, Takahiro Higuchi ${ }^{1}$, René M. Botnar ${ }^{1,5}$, Hans-Jürgen Wester ${ }^{1}$, and Markus Schwaiger ${ }^{1}$ \\ ${ }^{I}$ Nuklearmedizinische Klinik, Technischen Universität München, Munich, Germany; ${ }^{2}$ Faculty of Medicine, Cairo University, Egypt; \\ ${ }^{3}$ Turku PET Centre, University of Turku, Turku, Finland; ${ }^{4}$ Institute of Pathology, Technische Universität München, Munich, Germany; \\ and ${ }^{5}$ Division of Imaging Sciences, King's College London, London, United Kingdom
}

\begin{abstract}
${ }^{18} \mathrm{~F}$-galacto-RGD $\left({ }^{18} \mathrm{~F}-\mathrm{RGD}\right)$ is a PET tracer binding to $\alpha_{\mathrm{v}} \beta_{3}$ integrin receptors that are upregulated after myocardial infarction (MI) as part of the healing process. We studied whether myocardial ${ }^{18} \mathrm{~F}-\mathrm{RGD}$ uptake early after $\mathrm{MI}$ is associated with long-term left-ventricle (LV) remodeling in a rat model. Methods: Wistar rats underwent sham operation $(n=9)$ or permanent coronary ligation $(n=25)$. One week after MI, rats were injected with ${ }^{18} \mathrm{~F}-\mathrm{RGD}$ to evaluate $\alpha_{\mathrm{v}} \beta_{3}$ integrin expression using a preclinical PET system. In the same rats, LV volumes and defect size were measured 1 and 12 wk after $\mathrm{MI}$ by ${ }^{13} \mathrm{~N}$-ammonia PET and MRI, respectively. Results: One week after MI, ${ }^{18} \mathrm{~F}-\mathrm{RGD}$ uptake was increased in the defect area as compared with the remote myocardium of $\mathrm{MI}$ rats or sham-operated controls (percentage injected dose per cubic centimeter, $0.20 \pm 0.05$ vs. 0.06 \pm 0.03 and $0.07 \pm 0.04, P<0.001$ ). At this time, ${ }^{18} \mathrm{~F}-\mathrm{RGD}$ uptake was associated with capillary density in histologic sections. Average ${ }^{18} \mathrm{~F}-\mathrm{RGD}$ uptake in the defect area was lowest in the rats demonstrating greater than $20 \%$ relative increase in the LV end-diastolic volume from 1 to $12 \mathrm{wk}$ (percentage injected dose per centimeter cubed, $0.15 \pm 0.07$ vs. $0.21 \pm 0.05, P<$ 0.05). In a multivariable logistic regression analysis, low ${ }^{18} \mathrm{~F}-\mathrm{RGD}$ uptake was a significant predictor of increase in end-diastolic volume $(r=0.51, P<0.05)$. Conclusion: High levels of ${ }^{18} \mathrm{~F}-$ RGD uptake in the perfusion defect area early after MI were associated with the absence of significant LV remodeling after 12 wk of follow-up. These results suggest that $\alpha_{v} \beta_{3}$ integrin expression is a potential biomarker of myocardial repair processes after $\mathrm{Ml}$ and enables the monitoring of these processes by molecular imaging to derive possible prognostic information.
\end{abstract}

Key Words: ${ }^{18} \mathrm{~F}$-galacto-RGD; PET; LV remodeling; MRI; myocardial infarction

J Nucl Med 2012; 53:318-323

DOI: 10.2967/jnumed.111.091652

Received Apr. 11, 2011; revision accepted Sep. 22, 2011.

For correspondence or reprints contact: Hossam M. Sherif, Cairo University, Cairo, Egypt.

E-mail: hossam sherif66@hotmail.com

${ }^{*}$ Contributed equally to this work.

COPYRIGHT @ 2012 by the Society of Nuclear Medicine, Inc.
$\mathbf{M}$ tricle (LV) remodeling, is the most frequent cause for the tricle (LV) remodeling, is the most frequent cause for the development of chronic heart failure $(1,2)$. LV remodeling is characterized by complex cellular and structural alterations leading to progressive chamber dilatation and deterioration of cardiac function (2-4). The extent of myocardial damage is a major determinant of both prognosis and the risk of remodeling after MI (5,6). After initial cell death, myocardial tissue in the infarcted area undergoes a healing process associated with inflammation, angiogenesis, fibroblast proliferation, and collagen deposition resulting in scar formation (2). Poor infarct healing and infarct expansion during this phase can alter LV geometry, increase wall tension, and contribute to progressive remodeling $(2,7)$. Therefore, the components of infarct healing have been suggested as potential biomarkers to assess the risk of remodeling and target therapies to prevent an adverse outcome (8-11).

Integrin $\alpha_{v} \beta_{3}$ is a cell membrane glycoprotein receptor that is highly expressed on endothelial cells during angiogenesis. Its expression is upregulated after ischemic myocardial injury in the infarcted and border zone regions as part of the early infarct healing process (8-10). Radiolabeled antagonists containing the cyclic Arg-Gly-Asp (RGD) peptide have been used for molecular imaging of $\alpha_{v} \beta_{3}$ integrin expression after experimental and human MI using radionuclide imaging $(8,9,11)$. However, it remains unknown whether $\alpha_{\mathrm{v}} \beta_{3}$ integrin expression is associated with the post-MI LV remodeling process. Therefore, we studied whether ${ }^{18} \mathrm{~F}$-galacto-RGD ( ${ }^{18} \mathrm{~F}$-RGD) uptake early after $\mathrm{MI}$ is associated with long-term LV remodeling in a rat model. One week after permanent left coronary artery (LCA) ligation, rats were injected with ${ }^{18} \mathrm{~F}-\mathrm{RGD}$ to evaluate $\alpha_{\mathrm{v}} \beta_{3}$ integrin expression in the infarcted area using a small-animal PET scanner. In the same rats, changes in LV cavity size, LV function, and infarct size were studied by serial ${ }^{13} \mathrm{~N}$-ammonia $\left(\mathrm{NH}_{3}\right)$ PET and MRI measurements at 1 and $12 \mathrm{wk}$. Uptake of ${ }^{18} \mathrm{~F}$-RGD was compared with the presence of angiogenesis in histologic samples at $1 \mathrm{wk}$ after MI in a subgroup of rats. 


\section{MATERIALS AND METHODS}

\section{Study Protocol and Animal Model}

The study protocol is shown in Supplemental Figure 1 (supplemental materials are available online only at http://jnm. snmjournals.org). Permanent ligation of the LCA was performed in 50 healthy male Wistar rats (Charles Rivers Laboratories, Inc.) age $8-10$ wk to induce MI, whereas 9 controls had sham operation. Myocardial ${ }^{18}$ F-RGD uptake early after MI was evaluated by PET 1 wk after LCA ligation, because ${ }^{18} \mathrm{~F}-\mathrm{RGD}$ uptake is highest $1 \mathrm{wk}$ after MI (8). In the same imaging session, myocardial perfusion imaging was performed before ${ }^{18} \mathrm{~F}-\mathrm{RGD}$ injection to localize the myocardium and determine MI size. LV morphology and function were studied by MRI at $1 \mathrm{wk}$ ( $24 \mathrm{~h}$ after the PET) and 12 wk after LCA ligation. Subsequently, the rats were euthanized and hearts excised for histologic confirmation of MI size. In addition, a subgroup of rats with permanent $(n=3)$ or transient $(n=3)$ LCA ligation was injected with ${ }^{18} \mathrm{~F}-\mathrm{RGD}$ and euthanized $1 \mathrm{wk}$ after MI for ex vivo comparison of ${ }^{18} \mathrm{~F}-\mathrm{RGD}$ uptake using autoradiography and histologic determination of capillary density and inflammation in tissue sections.

Ligation of the LCA was done as previously described (12). Briefly, the rats were anesthetized with an intramuscular administration of midazolam (5 mg/kg, Dormicum; Roche), medetomidin $(0.5 \mathrm{mg} / \mathrm{kg}$, Dormitor; Pfizer), and fentanyl (0.05 mg/kg; Ratiopharm) and connected to a rodent ventilator. The heart was exposed through a left lateral thoracotomy of the fourth intercostal space, and the LCA was ligated near its origin $(\sim 2-3 \mathrm{~mm}$ from the tip of the left atrium). In the ischemia-reperfusion group, ligation was released after $20 \mathrm{~min}$. The sham operation consisted of the same procedures, except that the LCA suture was not tightened. The study protocols were approved by the regional governmental commission of animal protection (Regierung von Oberbayern, Germany).

\section{Tracer Preparation}

Synthesis of the precursor and ${ }^{18} \mathrm{~F}$ labeling of galacto-RGD was performed as described previously (13). Properties of radiolabeled RGD peptides have been recently reviewed by Haubner et al. (14).

\section{PET}

The rats were imaged using a small-animal PET scanner (Inveon; Siemens Medical Solutions) as described earlier $(8,12)$. The rats were anesthetized using $1.5 \%$ isoflurane, the electrocardiogram was monitored, and temperature was maintained using a heating pad throughout the imaging procedures. First, the rats were injected with $37 \mathrm{MBq}$ of $\mathrm{NH}_{3}$ in the tail vein, and perfusion images were acquired for $10 \mathrm{~min}$ starting $5 \mathrm{~min}$ after injection. Then, the rats were injected with $37 \mathrm{MBq}$ of ${ }^{18} \mathrm{~F}-\mathrm{RGD}$ in the tail vein without moving the animal between the $\mathrm{NH}_{3}$ and ${ }^{18} \mathrm{~F}-\mathrm{RGD}$ scans, and PET images were acquired for $30 \mathrm{~min}$ starting $90 \mathrm{~min}$ after injection.

Data were acquired in 3 dimensions and stored in list-mode format and sorted into a 3-dimensional sinogram, which was reconstructed using a 2-dimensional filtered backprojection algorithm with a ramp filter and cutoff at the Nyquist frequency $(0.5$ cycles/voxel). The resulting matrix was $128 \times 128$ pixels, with 95 transverse slices (voxel size, $0.43 \times 0.43 \times 0.80 \mathrm{~mm}^{3}$ ). Data were normalized and corrected for randoms, dead time, and decay. No corrections were made for attenuation or scatter.

\section{PET Image Analysis}

PET images were analyzed using the MunichHeart/NM software package (12). After manual definition of the long axis, myocardial contours in the $\mathrm{NH}_{3}$ PET images were automatically defined. To standardize delineation of myocardial contours throughout the LV, volumetric sampling and geometric constraints were used to optimize the quantification in the presence of large defects. For localization of MI and measurement of the defect size, $\mathrm{NH}_{3}$ activities of all sampling points were displayed as a polar map. Each polar map was normalized to a region of interest (ROI) in the remote myocardium. Then, the defect area was defined as the fraction of polar map elements with tracer uptake less than $50 \%$ of the maximum uptake and expressed as percentage of the total LV.

For quantification of ${ }^{18} \mathrm{~F}$-RGD uptake in the defect area and in the remote myocardium, the myocardial contours from the $\mathrm{NH}_{3}$ scan were copied to the coregistered ${ }^{18} \mathrm{~F}-\mathrm{RGD}$ data. Then, the generation of ${ }^{18} \mathrm{~F}$-RGD polar maps was repeated using matching image orientation and sampling points. The ROIs in the $\mathrm{NH}_{3}$ polar maps delineating the defect area and remote myocardium were then copied to the ${ }^{18} \mathrm{~F}-\mathrm{RGD}$ polar maps to allow precise spatially matched quantification of ${ }^{18} \mathrm{~F}-\mathrm{RGD}$ activity. The mean radioactivity concentration within the ${ }^{18} \mathrm{~F}-\mathrm{RGD}$ ROI was converted to Bq/ cubic centimeter and expressed as percentage of injected dose per tissue cubic centimeter $\left(\% \mathrm{ID} / \mathrm{cm}^{3}\right)$ assuming constant density of the cardiac tissue.

\section{Cardiac MRI}

Electrocardiogram-gated cardiac MRI was a 1.5-T Philips Achieva MRI scanner (Philips Medical System) connected to a small-animal electrocardiogram triggering system (SA Instruments) and a small 47-mm flex loop coil as previously described (15). The rats were anesthetized with intramuscular injection of midazolam $(0.15 \mathrm{mg} / \mathrm{kg})$, medetomidin $(2 \mathrm{mg} / \mathrm{kg})$, and fentanyl $(0.005 \mathrm{mg} / \mathrm{kg})$. The heart rate was between 180 and 210 beats per minute during the scan. With the rat in the prone position, short-axis images were acquired using a turbo field echo sequence with the following parameters: repetition time, $14 \mathrm{~ms}$; echo time, $4.5 \mathrm{~ms}$; flip angle, $30^{\circ}$; in-plane resolution, $0.31 \times 0.31 \mathrm{~mm}$; and slice thickness, $2 \mathrm{~mm}$ with contiguous slices.

The MunichHeart/MR software package was used for the quantitative MRI analysis (15). Endo- and epicardial contours of the LV slices were manually traced in end-diastole and end-systole. Then, LV end-diastolic volume (EDV) and end-systolic volume (ESV), ejection fraction (EF), and global wall thickening (WT) were calculated. Volumes were corrected for body weight at the time of imaging for comparison of serial measurements. On the basis of results from clinical and experimental data $(4,6), \mathrm{LV}$ remodeling was defined as a greater than $20 \%$ increase in EDV between baseline and 12-wk MRI measurements.

\section{Ex Vivo Pathologic Analysis}

The rats were euthanized using an intravenous injection of pentobarbiturate $(150 \mathrm{mg} / \mathrm{kg}$, Narcoren; Merial). The heart was excised and sliced along its short axis into four approximately 1- to 2-mm slices, from the apex to the base. The slices were incubated in $1 \%$ 2,3,5-triphenyltetrazolium chloride (TTC) solution at $37^{\circ} \mathrm{C}$ for $20 \mathrm{~min}$ and photographed from both sides. The infarct size was measured as the average percentage of LV circumference occupied by the infarct scar using software (ImageJ 1.43n; National Institutes of Health) (Supplemental Fig. 2). The presence of MI was defined as infraction involving greater than $4 \%$ of the endocardial circumference (16). Further, 5 - $\mu$ m-thick cryosections of the heart were prepared. Serial 5- $\mu$ m sections were stained with hematoxylin and eosin and with Masson trichrome 
(Sigma-Aldrich, Germany) to distinguish the collagen from the muscle tissue.

\section{Autoradiography and Immunohistochemical Analysis}

For the localization of ${ }^{18} \mathrm{~F}-\mathrm{RGD}$ uptake, a subgroup of 6 rats was injected with $37 \mathrm{MBq}$ of ${ }^{18} \mathrm{~F}-\mathrm{RGD}$ and euthanized $90 \mathrm{~min}$ later $1 \mathrm{wk}$ after MI. The hearts were excised, frozen, and embedded in methylcellulose. Serial LV short-axis cryosections of 20- and 6- $\mu \mathrm{m}$ thicknesses were obtained at approximately 1- to 2-mm intervals from the apex to the base covering the entire heart. Accumulated ${ }^{18} \mathrm{~F}$ activity in the sections was measured using digital autoradiography.

After careful coregistration of the autoradiographs and histologic images, regional tracer uptake was analyzed in ROIs located in the center of the infarcted myocardium and in the remote noninfarcted myocardium and expressed as background-corrected photostimulated luminescence units. Vascular and macrophage densities in the same ROIs were determined by CD31 (BD PharMingen) and CD68 (MAC-3; BD Pharmingen) immunohistochemical staining using a 3-point scoring system performed by a pathologist, masked to the results of tracer uptake study.

\section{Statistical Analysis}

All data are expressed as mean $\pm \mathrm{SD}$. For comparison between 2 time points or groups, a Student $t$ test for paired or unpaired data was used. For correlation between 2 continuous variables, linear regression with Spearman rank test was used. A multivariate linear regression model, including ${ }^{18} \mathrm{~F}-\mathrm{RGD}$ uptake, residual $\mathrm{NH}_{3}$ uptake, MI size, ESV, and EDV, was used to identify independent predictors of the increase in EDV from 1 to $12 \mathrm{wk} . P$ values less than 0.05 were considered statistically significant.

\section{RESULTS}

Of the 50 rats with coronary ligation, 28 survived (19 died during the first week) the 12 -wk study protocol. Three rats with ligation were excluded, because no MI $(<4 \%$ of the LV in histology after $12 \mathrm{wk}$ ) was detected. Thus, in addition to the 9 sham-operated controls, the final study group consisted of 25 animals with permanent LCA ligation (plus 6 rats used for ex vivo analyses only). Average body weights increased from $352 \pm 42 \mathrm{~g}$ at $1 \mathrm{wk}$ to $515 \pm 43 \mathrm{~g}$ at $12 \mathrm{wk}$ after MI $(P<0.001)$ and from $381 \pm 28 \mathrm{~g}$ at $1 \mathrm{wk}$ to $543 \pm 74 \mathrm{~g}$ at 12 wk after the sham operation $(P<0.001)$.

At 12 wk after MI, sham-operated rats showed no MI. In the group of 25 rats with LCA ligation, 20 showed fully transmural MI scarring (Supplemental Fig. 2). Average MI size was $29.7 \% \pm 6.9 \%$ (range, $14 \%-43 \%$ ) of the LV. Defect size in $\mathrm{NH}_{3}$ PET images increased from $1 \mathrm{wk}(25.6 \% \pm$ $9 \%)$ to $12 \mathrm{wk}(28.9 \% \pm 8.3 \%)$. PET image-derived defect size and MI size by TTC staining showed good correlation $\left(r_{\text {Spearman }}=0.89, P<0.001\right)$ at $12 \mathrm{wk}$.

\section{In Vivo Imaging of Myocardial ${ }^{18} \mathrm{~F}-\mathrm{RGD}$ Uptake After MI}

There was low ${ }^{18} \mathrm{~F}$-RGD uptake in the hearts of shamoperated rats, but focally increased ${ }^{18} \mathrm{~F}$-RGD uptake was seen in the anterior and lateral LV wall after LCA ligation (Fig. 1). Polar maps demonstrated homogeneous $\mathrm{NH}_{3}$ and ${ }^{18} \mathrm{~F}-\mathrm{RGD}$ distribution throughout $\mathrm{LV}$ myocardium in all sham-operated rats. In contrast, sometimes patchy areas of increased ${ }^{18} \mathrm{~F}$-RGD uptake throughout the area of $\mathrm{NH}_{3}$ defect after LCA ligation that was clearly distinct from liver uptake and uptake in the surgical wound in the chest wall were observed (Fig. 1). Average ${ }^{18}$ F-RGD uptake was higher in the defect area than in the remote myocardium of MI rats or in sham-operated rats $(0.20 \pm 0.05$ vs. $0.06 \pm$ 0.03 and $0.07 \pm 0.04 \% \mathrm{ID} / \mathrm{cm}^{3}, P<0.001$ and $P<0.001$, respectively) (Fig. 2). A moderate correlation was found between ${ }^{18} \mathrm{~F}$-RGD uptake and the residual $\mathrm{NH}_{3}$ uptake in the defect area $\left(r_{\text {Spearman }}=0.46, P<0.05\right)$ (Supplemental Fig. 3A). However, there was no correlation between PET defect size and ${ }^{18}$ F-RGD uptake (Supplemental Fig. 3B).
FIGURE 1. Examples of PET and MR images of rats with $\mathrm{Ml}$ and less than $20 \%$ increase in EDV (left), rat with $\mathrm{Ml}$ and greater than $20 \%$ increase of EDV (middle), and sham-operated control rat (right). (A) Separate and fused coregistered $\mathrm{NH}_{3}$ and ${ }^{18} \mathrm{~F}$ RGD tomograms. (B) $\mathrm{NH}_{3}$ polar maps and coregistered ${ }^{18} \mathrm{~F}-\mathrm{RGD}$ polar maps. Each $\mathrm{NH}_{3}$ polar map was normalized to its remote myocardium uptake (as maximum uptake) and defect area ROI was defined using $50 \%$ threshold. Then both remote and defect $\mathrm{ROls}$ were coregistered to ${ }^{18} \mathrm{~F}-\mathrm{RGD}$ polar map using same axes to evaluate ${ }^{18} \mathrm{~F}-\mathrm{RGD}$ uptake in infarcted and remote myocardium. Uptake of ${ }^{18} \mathrm{~F}-\mathrm{RGD}$ in infracted area in rat with less than $20 \%$ increase in EDV is higher than in rat with greater than $20 \%$ increase in EDV. In $\mathrm{B}$, increased $\mathrm{NH}_{3}$ and RGD activity in inferior wall in all maps near apex, represent-

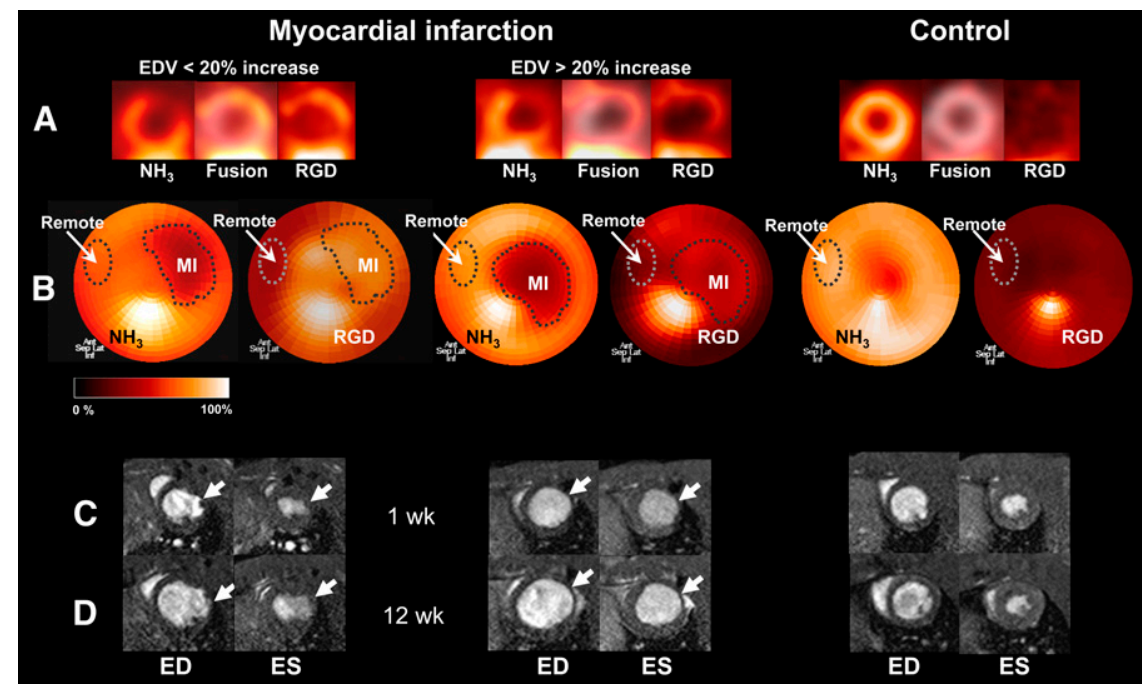

ing activity spillover from liver. (C) Representative cross-sectional MR images of LV during end-diastole (ED) and end-systole (ES) 1 wk after MI. (D) Corresponding images of same rats $12 \mathrm{wk}$ after MI. Ant = anterior; Inf = inferior; Lat = lateral; Sep = septal. 


\section{Autoradiography and Tissue Histology}

All of the 6 rats subjected to ex vivo examinations at $1 \mathrm{wk}$ after MI survived and showed infarction. Irrespective of reperfusion, autoradiography confirmed $3.9 \pm 1.5$ times higher ${ }^{18} \mathrm{~F}-\mathrm{RGD}$ uptake in the infarcted area than in the remote myocardium of the same rats and $3.4 \pm 1.3$ times higher uptake in the infracted area than in the sham-operated controls (Supplemental Fig. 4). ${ }^{18}$ F-RGD uptake ratio was strongly correlated with CD31-positive microvessel density in the infarcted area $\left(r_{\text {Spearman }}=0.83, P<0.05\right)$ but showed an inverse correlation with CD68-positive macrophage density $\left(r_{\text {Spearman }}=-0.81, P<0.05\right)$ (Supplemental Fig. 4).

\section{Long-Term LV Function and Remodeling After MI}

The MR images and results are shown in Figure 1 and Table 1. Compared with the sham-operated rats, body weight-corrected EDV and ESV were higher in the MI group than in sham-operated group at 12 wk. Global EF and WT were lower in the MI group than in the sham group at both 1 and 12 wk after infarction.

In the sham-operated rats EDV and ESV remained unchanged from 1 wk to 12 wk. In contrast, EDV and ESV increased from $1 \mathrm{wk}$ to $12 \mathrm{wk}$ in the MI group $(10.6 \%, P<$
0.05 and $14.3 \%, P<0.001$, respectively). Global EF and WT were comparable at 1 and $12 \mathrm{wk}$.

There was significant LV remodeling-that is, a greater than $20 \%$ increase in the EDV from $1 \mathrm{wk}$ to $12 \mathrm{wk}$ in 10 rats. In these rats, average EDV increased from $0.37 \pm 0.04 \mu \mathrm{L} / \mathrm{g}$ at $1 \mathrm{wk}$ to $0.51 \pm 0.05 \mu \mathrm{L} / \mathrm{g}$ at $12 \mathrm{wk}(P<0.001)$ and ESV from $0.21 \pm 0.04 \mu \mathrm{L} / \mathrm{g}$ to $0.29 \pm 0.05 \mu \mathrm{L} / \mathrm{g}(P<0.001)$. However, EF remained comparable $(42 \pm 10$ vs. $44 \% \pm$ $9 \%)$. In rats with no remodeling $(<20 \%$ increase in EDV), the average EDV, ESV, and EF were comparable at 1 and 12 wk after MI $(0.46 \pm 0.07$ vs. $0.44 \pm 0.07 \mu \mathrm{L} / \mathrm{g}, 0.26 \pm$ 0.07 vs. $0.26 \pm 0.08 \mu \mathrm{L} / \mathrm{g}$, and $44 \% \pm 10 \%$ vs. $41 \% \pm$ $12 \%$, respectively).

\section{Early ${ }^{18}$ F-RGD Uptake, MI Size, LV Function, and Remodeling}

In the rats with significant remodeling (i.e., $>20 \%$ increase in EDV), average ${ }^{18} \mathrm{~F}$-RGD uptake at $1 \mathrm{wk}$ in the defect area was lower than in other rats $(0.15 \pm 0.07$ vs. $0.21 \pm 0.05 \% \mathrm{ID} / \mathrm{cm}^{3}, P<0.05$ [Fig.2]). Figure 1 shows examples of PET and MR images in rats with less than $20 \%$ and greater than $20 \%$ increases in EDV.

Uptake of ${ }^{18} \mathrm{~F}$-RGD in the defect area correlated inversely with changes in the $\operatorname{EDV}\left(r_{\text {Spearman }}=-0.66, P<0.001\right)$,

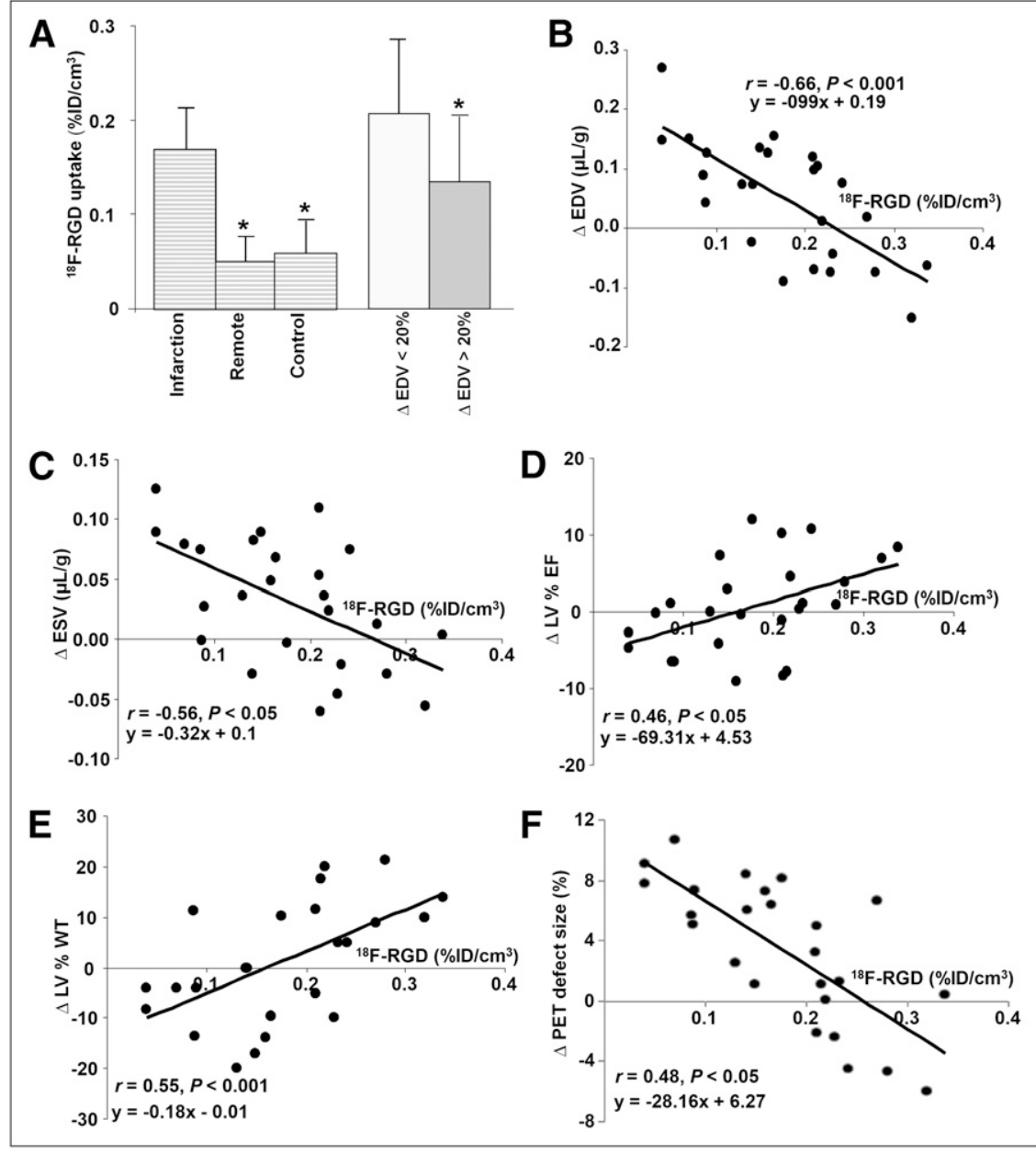

FIGURE 2. (A) Average ${ }^{18} \mathrm{~F}-\mathrm{RGD}$ uptake in infarcted myocardium was higher than that in remote myocardium of MI rats or shamoperated rats at $1 \mathrm{wk}$ after MI. Furthermore, average ${ }^{18} \mathrm{~F}-\mathrm{RGD}$ uptake in infarcted myocardium was higher, but defect sizes were smaller in rats with greater than $20 \%$ than in rats with less than $20 \%$ increase in EDV $(\Delta$ EDV) $\left({ }^{\star} P<0.05\right)$. Scatterplots demonstrate that there were correlations between ${ }^{18} \mathrm{~F}$ RGD uptake at $1 \mathrm{wk}$ after $\mathrm{MI}$ and changes in $\operatorname{EDV}(\mathrm{B})$, ESV (C), EF (D), WT (E), and $\mathrm{NH}_{3}$ PET defect size (F) from 1 wk to 12 wk after MI. Uptake of ${ }^{18} \mathrm{~F}-\mathrm{RGD}$ in defect area correlated inversely with change in EDV, ESV, and $\mathrm{NH}_{3}$ PET defect size but directly with change in percentage EF and percentage WT from $1 \mathrm{wk}$ to $12 \mathrm{wk}$. High ${ }^{18} \mathrm{~F}-\mathrm{RGD}$ uptake at $1 \mathrm{wk}$ after MI predicted improvement in LV function, less increase in MI size, and less increase in LV size. 
TABLE 1

Results of MRI in Rats with MI or Sham Operation

\begin{tabular}{|c|c|c|c|c|}
\hline \multirow[b]{2}{*}{ LV parameters } & \multicolumn{2}{|c|}{$\mathrm{Ml}$} & \multicolumn{2}{|c|}{ Sham } \\
\hline & $1 \mathrm{wk}$ & $12 \mathrm{wk}$ & $1 \mathrm{wk}$ & $12 w k$ \\
\hline $\mathrm{EDV}(\mu \mathrm{L})$ & $147 \pm 27$ & $241 \pm 46^{\star}$ & $128 \pm 5^{\dagger}$ & $161 \pm 16^{\dagger}$ \\
\hline EDV/body weight $(\mu \mathrm{L} / \mathrm{g})$ & $0.42 \pm 0.07$ & $0.47 \pm 0.07^{\star}$ & $0.33 \pm 0.03$ & $0.32 \pm 0.06^{\dagger}$ \\
\hline ESV $(\mu L)$ & $128 \pm 5$ & $161 \pm 16^{*}$ & $44 \pm 4^{\dagger}$ & $56 \pm 7^{\dagger}$ \\
\hline ESV/body weight $(\mu \mathrm{L} / \mathrm{g})$ & $0.24 \pm 0.07$ & $0.27 \pm 0.07^{\star}$ & $0.11 \pm 0.01$ & $0.11 \pm 0.02^{\dagger}$ \\
\hline EF (\%) & $43 \pm 10$ & $43 \pm 11$ & $67 \pm 12^{\dagger}$ & $66 \pm 10^{\dagger}$ \\
\hline WT (\%) & $34 \pm 8$ & $32 \pm 9$ & $65 \pm 4^{\dagger}$ & $64 \pm 6^{\dagger}$ \\
\hline $\begin{array}{l}{ }^{\star} P<0.051 \text { wk vs. } 12 \text { wk } \\
{ }^{\dagger} P<0.05 \mathrm{Ml} \text { vs. sham o }\end{array}$ & & & & \\
\hline
\end{tabular}

$\operatorname{ESV}\left(r_{\text {Spearman }}=-0.56, P<0.05\right)$, and PET defect size $\left(r_{\text {Spearman }}=-0.74, P<0.001\right)$ but directly with changes in $\mathrm{EF}\left(r_{\text {Spearman }}=0.46, P<0.05\right)$ and $\mathrm{WT}\left(r_{\text {Spearman }}=0.55\right.$, $P<0.05$ ) from $1 \mathrm{wk}$ to $12 \mathrm{wk}$ after MI (Fig. 2). There was also a correlation between MI size (assessed by either TTC or PET) after $12 \mathrm{wk}$ and the change in EDV ( $r_{\text {Spearman }}=$ $0.48, P<0.05)$. However, unlike ${ }^{18} \mathrm{~F}$-RGD uptake, the defect size at 1 wk was not significantly correlated with change in $\operatorname{EDV}(r=-0.01, P=$ not significant).

In a multivariate linear regression model including ${ }^{18} \mathrm{~F}$ RGD uptake in the infarcted area, residual $\mathrm{NH}_{3}$ uptake in the infracted area, MI size, ESV, EDV, and ${ }^{18}$ F-RGD uptake remained a significant predictor of the increase in EDV from $1 \mathrm{wk}$ to $12 \mathrm{wk}$ (Table 2).

TABLE 2

Multivariable Predictors of LV Remodeling (Change in EDV from 1 to 12 Weeks) at 1 Week After MI

\begin{tabular}{lcc}
\hline \multicolumn{1}{c}{ Findings } & Standardized coefficient & $P$-value \\
\hline PET & & \\
Residual $\mathrm{NH}_{3}$ uptake & 0.021 & 0.904 \\
MI size & 0.243 & 0.169 \\
RGD uptake & -0.509 & 0.013 \\
MRI & & \\
EDV & -0.744 & 0.385 \\
ESV & 0.258 & 0.839 \\
EF & 0.184 & 0.825 \\
\hline
\end{tabular}

\section{DISCUSSION}

We found that high levels of ${ }^{18} \mathrm{~F}-\mathrm{RGD}$ uptake in the infarcted area early after MI were associated with the absence of LV remodeling after 12 wk of follow-up. One week after MI, increased $\alpha_{v} \beta_{3}$ integrin expression associated with angiogenesis and infarct healing could be assessed using PET of ${ }^{18}$ F-RGD uptake. Serial MRI measurements at 1 and 12 wk showed marked dilatation of LV consistent with remodeling. In these rats, ${ }^{18} \mathrm{~F}-\mathrm{RGD}$ uptake in the infarcted area inversely correlated with LV dilatation and directly corre- lated with worsening of systolic function. Low ${ }^{18} \mathrm{~F}-\mathrm{RGD}$ uptake was an independent predictor of subsequent LV dilatation. These results provide the first evidence that $\alpha_{\mathrm{v}} \beta_{3}$ integrin expression could enable monitoring of myocardial repair after MI by molecular imaging, potentially enabling the assessment of relevant prognostic information.

\section{RGD Imaging}

${ }^{18} \mathrm{~F}-\mathrm{RGD}$ is a PET tracer containing the cyclic RGD peptide that binds to $\alpha_{\mathrm{v}} \beta_{3}$ integrin with high selectivity $(12,17)$. We have found increased ${ }^{18} \mathrm{~F}$-RGD uptake in rat model of myocardial ischemia-reperfusion in the infarcted and border-zone areas (8). The uptake was efficiently blocked by predosing with a nonlabeled probe, confirming the biologic specificity of uptake (8). Peak ${ }^{18}$ F-RGD uptake occurred from 1 wk to $3 \mathrm{wk}$ after MI (8). Thus, we planned the presented study based on dual-isotope imaging of perfusion with $\mathrm{NH}_{3}$ and $\alpha_{\mathrm{v}} \beta_{3}$ integrin expression with ${ }^{18} \mathrm{~F}-\mathrm{RGD}$. Our findings confirm the feasibility of imaging focal ${ }^{18} \mathrm{~F}-\mathrm{RGD}$ uptake in 1-wk-old infarctions after permanent coronary occlusion $(8,14)$ in rats as well as in human-reperfused MI $(11)$.

One week after LCA ligation, ${ }^{18}$ F-RGD uptake was strongly associated with capillary density in the infarcted area, as assessed with histologic studies. This is consistent with previous findings with both ${ }^{18} \mathrm{~F}-\mathrm{RGD}$ and another RGDbased tracer labeled with ${ }^{111}$ In $(8,9)$. However, we did not find a correlation between macrophage density and the amount of ${ }^{18} \mathrm{~F}$-RGD uptake in the infarcted area that has been shown with some matrix metalloproteinase-targeted tracers (18). Van de Borne et al. found that their RGD tracer was also bound to myofibroblasts in the infarcted area at 2 wk after MI by fluorescent microscopy of tissue sections (10).

\section{${ }^{18}$ F-RGD Uptake and LV Remodeling}

We used an established rat model of coronary ligation to study post-MI LV remodeling (19). Consistent with previous studies, MRI showed pronounced increase $(>20 \%)$ in $\mathrm{LV}$ volume from $1 \mathrm{wk}$ to $12 \mathrm{wk}$, even after moderate-sized MI $(20 \%-40 \%$ of the LV circumference) $(2,4,19)$. Uptake of ${ }^{18} \mathrm{~F}-\mathrm{RGD}$ remained an independent predictor of the in- 
crease in LV size even after other well-known predictors of remodeling, including MI size, residual tissue perfusion, EF, ESV, and EDV, were considered. To our knowledge, this is the first study demonstrating that ${ }^{18} \mathrm{~F}$-RGD uptake early after MI predicts subsequent LV remodeling. Consistent with this, a high level of ${ }^{18} \mathrm{~F}-\mathrm{RGD}$ uptake $1 \mathrm{wk}$ after MI was associated with no expansion of the perfusion defect from $1 \mathrm{wk}$ to 12 wk after MI, supporting the role of $\alpha_{\mathrm{v}} \beta_{3}$ integrin as a mediator of the infarct healing process. These results indicate that $\alpha_{\mathrm{v}} \beta_{3}$ integrin expression is a potential biomarker for the myocardial infarct healing during the granulation tissue formation, possibly allowing noninvasive imaging with ${ }^{18} \mathrm{~F}-\mathrm{RGD}$ PET to predict the success of the interventional procedures. The finding may open new possibilities to predict adverse outcomes and optimized, targeted therapies.

\section{Study Limitations}

We are aware of some limitations in our study. The permanent LCA ligation results in extensive cell death and fully transmural infarct scarring in the rat model. However, this is often not the case in the clinical situation, when early reperfusion limits cell death. Therefore, the predictive value of ${ }^{18} \mathrm{~F}$-RGD needs to be confirmed in different models, allowing standardization of the contributions of different pathophysiologic variables. The predictive value may also depend on the use of medications and timing of imaging, which need to be carefully evaluated in patient studies.

Our study protocol did not allow comparison of ${ }^{18} \mathrm{~F}-\mathrm{RGD}$ with other imaging markers with known predictive value after $\mathrm{MI}$, such as detection of viable myocardium with ${ }^{18} \mathrm{~F}$-FDG. There was a clear association between ${ }^{18} \mathrm{~F}-\mathrm{RGD}$ uptake and residual perfusion as assessed by uptake of $\mathrm{NH}_{3}$, which may reflect the presence of inflammation in that area. Because of constraints in spatial resolution and tissue contrast in our clinical 1.5-T MRI scanner, we were not able to evaluate the extent of delayed enhancement in the infarcted area $1 \mathrm{wk}$ after MI. In future studies, evaluation of this extent could allow more direct comparisons of the contributions of MI size and ${ }^{18} \mathrm{~F}-$ RGD on the likelihood of LV remodeling. These studies should also involve a larger number of subjects.

\section{CONCLUSION}

Our results suggest that $\alpha_{v} \beta_{3}$ integrin expression is associated with myocardial repair after MI and enables its monitoring by molecular imaging to delineate prognostic information. Molecular imaging of $\alpha_{\mathrm{v}} \beta_{3}$ integrin expression may offer an attractive imaging signal to improve risk assessment of postMI patients and may serve as a biomarker for targeted therapy.

\section{DISCLOSURE STATEMENT}

The costs of publication of this article were defrayed in part by the payment of page charges. Therefore, and solely to indicate this fact, this article is hereby marked "advertisement" in accordance with 18 USC section 1734.

\section{ACKNOWLEDGMENTS}

This work was supported by EC-FP6-project DiMI (LSHBCT-2005-512146) and in part by an Unrestricted Cardiovascular Research grant from Bristol-Myers Squibb Foundation. No other potential conflict of interest relevant to this article was reported.

\section{REFERENCES}

1. McMurray JJ, Pfeffer MA. Heart failure. Lancet. 2005;365:1877-1889.

2. Pfeffer MA, Braunwald E. Ventricular remodeling after myocardial infarction: experimental observations and clinical implications. Circulation. 1990;81:11611172 .

3. Anversa P, Olivetti G, Capasso JM, et al. Cellular basis of ventricular remodeling after myocardial infarction. Am J Cardiol. 1991;68:7D-16D.

4. Nahrendorf M, Wiesmann F, Hiller KH, et al. Serial cinemagnetic resonance imaging of left ventricular remodeling after myocardial infarction in rats. J Magn Reson Imaging. 2001;14:547-555.

5. St John Sutton M, Pfeffer MA, Moye L, et al. Cardiovascular death and left ventricular remodeling two years after myocardial infarction: baseline predictors and impact of long-term use of captopril. Circulation. 1997;96:3294-3299.

6. Bolognese L, Neskovic AN, Parodi G, et al. Left ventricular remodeling after primary coronary angioplasty: patterns of left ventricular dilation and long-term prognostic implications. Circulation. 2002;106:2351-2357.

7. Heymans S, Luttun A, Nuyens D, et al. Inhibition of plasminogen activators or matrix metalloproteinases prevents cardiac rupture but impairs therapeutic angiogenesis and causes cardiac failure. Nat Med. 1999;5:1135-1142.

8. Higuchi T, Bengel FM, Seidl S, et al. Assessment of $\alpha v \beta 3$ integrin expression after myocardial infarction by positron emission tomography. Cardiovasc Res. 2008;78:395-403.

9. Meoli DF, Sadeghi MM, Krassilnikova S, et al. Noninvasive imaging of myocardial angiogenesis following experimental myocardial infarction. J Clin Invest. 2004;113:1684-1691.

10. van den Borne SWM, Isobe S, Verjans JW, et al. Molecular imaging of interstitial alterations in remodeling myocardium after myocardial infarction. J Am Coll Cardiol. 2008;52:2017-2028

11. Makowski MR, Ebersberger U, Nekolla S, et al. In vivo molecular imaging of angiogenesis, targeting $\alpha \mathrm{v} \beta 3$ integrin expression, in a patient after acute myocardial infarction. Eur Heart J. 2008;29:2201.

12. Sherif HM, Saraste A, Weidl E, et al. Evaluation of a novel ${ }^{18} \mathrm{~F}$-labeled positronemission tomography perfusion tracer for the assessment of myocardial infarct size in rats. Circ Cardiovasc Imaging. 2009;2:77-84.

13. Haubner R, Kuhnast B, Mang C, et al. ${ }^{18} \mathrm{~F}$-galacto-RGD: synthesis, radiolabeling, metabolic stability, and radiation dose estimates. Bioconjug Chem. 2004;15: 61-69.

14. Haubner R, Beer AJ, Wang H, et al. Positron emission tomography tracers for imaging angiogenesis. Eur J Nucl Med Mol Imaging. 2010;37:S86-S103.

15. Stein A, Knödler M, Makowski M, et al. Local erythropoietin and endothelial progenitor cells improve regional cardiac function in acute myocardial infarction. BMC Cardiovasc Disord. 2010; 17:10:43.

16. Pfeffer MA, Pfeffer JM, Fishbein MC, et al. Myocardial infarct size and ventricular function in rats. Circ Res. 1979;44:503-512.

17. Haubner R, Weber WA, Beer AJ, et al. Noninvasive visualization of the activated $\alpha v \beta 3$ integrin in cancer patients by positron emission tomography and ${ }^{18} \mathrm{~F}$ galacto-RGD. PLoS Med. 2005;2:e70.

18. Chen J, Tung CH, Allport JR, et al. Near-infrared fluorescent imaging of matrix metalloproteinase activity after myocardial infarction. Circulation. 2005;111: 1800-1805.

19. Pfeffer JM, Pfeffer MA, Fletcher PJ, et al. Progressive ventricular remodeling in rat with myocardial infarction. Am J Physiol. 1991;260:H1406-H1414. 